\begin{tabular}{|c|c|}
\hline Title & Effectiveness of recycled nylon fiber from waste fishing net with respect to fiber reinforced mortar \\
\hline Author(s) & Orasutthikul, Shanya; Unno, Daiki; Y okota, Hiroshi \\
\hline Citation & $\begin{array}{l}\text { Construction and building materials, 146, 594-602 } \\
\text { https://doi.org/10.1016/.conbuildmat.2017.04.134 }\end{array}$ \\
\hline Issue Date & $2017-08-15$ \\
\hline Doc URL & http:/hdl.handle.net/2115/75235 \\
\hline Rights & $\begin{array}{l}\text { () 2017, Elsevier. Licensed under the Creative Commons A ttribution-NonCommercial-NoD erivatives } 4.0 \text { International } \\
\text { http://creativecommons.org/icenses/oy-nc-nd/4.0/ }\end{array}$ \\
\hline Rights(URL) & http://creativecommons.org/icenses/by-nc-nd/4.0/ \\
\hline Type & article (author version) \\
\hline File Information & Journal_ConBuildMat_R1.pdf \\
\hline
\end{tabular}

Instructions for use 


\section{Effectiveness of recycled nylon fiber from waste fishing net 2 with respect to fiber reinforced mortar}

3 Shanya Orasutthikul, Daiki Unno, Hiroshi Yokota

$4 \quad$ Hokkaido University, Japan

6 Abstract

7 This paper discusses the utilization of recycle waste fishing nets in fiber reinforced mortar.

8 Experimental test results compared the mechanical properties of such mortar made with

9 recycled nylon fiber to those of such mortar made with recycled PET and PVA (polyvinyl

10 alcohol) short fibers. The recycled nylon (R-Nylon) fibers were obtained by manually cutting of

11 waste fishing nets to the lengths of $20 \mathrm{~mm}, 30 \mathrm{~mm}$ and $40 \mathrm{~mm}$. Two types of R-Nylon fibers

12 were investigated that are straight and knotted types. The addition of straight R-Nylon fiber

13 improved the flexural strength up to $41 \%$ in comparison with that of the knotted R-Nylon,

14 recycled PET, and PVA fibers. The compressive strength of the mortar with R-Nylon fiber

15 decreased with increase in fiber fraction and length. The post peak load, toughness and residual

16 strength depended on the properties of fiber such as Young's modulus, tensile strength, and

17 geometry as well as the bond strength between fiber and matrix.

18 Keywords: Fiber reinforced mortar, recycled nylon fiber, waste fishing nets, synthetic short fiber, 
strength, toughness.

\section{Introduction}

4 Marine debris is one of the major problems in the sea and ocean environment. It has been reported

5 that more than half of the debris that were dumped or lost directly into the seas, about 640,000

6 tons, are fishing nets [1]. Almost 700 marine species including marine mammals are at risk; in

7 particular, large whales, seals, and sea lions have been found entangled in the fishing nets [2].

8 These abandoned fishing nets and debris also disturb marine ecosystem. They block sunlight to

9 reach smallest creatures in the sea, which directly affects marine animals that feed on smallest

creatures such as algae and plankton. Nowadays, fishing nets are mostly made of nylon which is

non-biodegradable, and totally entangled fishing nets are very difficult to be separated. Therefore,

there have been strong calls for recycling waste fishing nets. To meet such demands, a practical, suitable way to recycle them has been sought by many companies, while using recycled and renewable materials have been paid more attention [3]. The waste fishing nets are used in manufactures of carpet tiles, as well as they are melted and then used in manufactures of bicycle seats, chair and luggage castors, tool handles, electronics components, and other goods [4]. The nets have been also used in civil engineering field as a recycled fiber in order to reinforce or strengthen concrete, mortar and soil [5, 6]. Even during the past three decades, the use of synthetic 
1 fiber, such as polyvinyl alcohol (PVA) fiber and polypropylene fiber has been paid attention, and

2 it is successful in significantly improving mechanical properties, such as flexural strength,

3 fracture toughness, and impact resistance, of fiber reinforced mortar and concrete [7-22].

4 However, using of those fibers surely leads to higher energy consumption and emission for

5 production process [6]. Accordingly, many researchers have been concerning and focusing on

6 using recycled materials [21, 23-29], in recent years. Kim et al. [5] studied the mechanical

7 properties of reinforced lightweight soil (RLS) by using waste fishing nets. They found that using

8 waste fishing nets at $0.25 \%$ by weight of soil makes unconfined compressive strength of RLS

$9 \quad 2-2.5$ times higher than that of untreated lightweight soil. Spadea et al. [6] investigated the static

10 mechanical properties of fiber reinforced mortar by using recycled nylon fiber from abandoned

11 fishing nets. They found that the toughness and ductility are significantly improved by the

12 addition of recycled fiber to the mortar, and the flexural strength is improved up to $35 \%$. Alkali

13 degradation of the nylon fiber may occur if it is mixed with cement, which results in reduction in

14 strength and toughness of the fiber reinforced concrete. Ochi et al. [30] investigated the alkali

15 resistance of synthetic fibers such as PET, polypropylene and PVA fibers by doing immersion

16 tests into alkali solution. They found that tensile strength of PET, polypropylene and PVA fibers

17 decrease $99 \%$, 86\% and 56\% of respective virgin fibers. For the recycled nylon fiber, Spadea et al.

18 [6] found that its tensile strength decreases only about $4 \%$ by the exposure to an alkali 
1 environment. The authors previously conducted a comparative experimental research on the

2 effectiveness of recycled nylon fiber and PVA fiber reinforced mortar [31]. The research

3 concluded that recycled nylon fiber has a potential to improve the mechanical properties of

4 mortar.

5 This paper investigates in detail the effectiveness of recycled nylon fibers from waste fishing nets

6 when they are mixed into mortar. Change in flow diameters of fresh mortar was investigated to

7 discuss the workability of the fiber reinforced mortar. Compressive and flexural strengths of the

8 recycled nylon fiber reinforced mortar were measured and compared with those of mortar with

9 recycled PET and PVA fibers that have been frequently used as reinforcing materials of mortar

10 and concrete. In addition, the surfaces of fibers after the bending test were carefully observed by

11 using microscope to understand the mechanism of the mechanical properties improvement.

\section{2. Experimental program}

\subsection{Mixture composition and preparation}

15 The recycled nylon fiber examined in this study was prepared by manually cutting waste fishing

16 nets collected by fishermen in Hokkaido, see Figure 1(a). The cutting was started after washing

17 the net by tap water. The two fiber types were made; that is, straight fiber and knotted fiber, see

18 Figures 1 (b) and 1(c), respectively. The straight fiber was $20 \mathrm{~mm}$, $30 \mathrm{~mm}$ or $40 \mathrm{~mm}$ long, and 
1 was mixed in mortar at the volume fractions of $1.0 \%, 1.5 \%$ and $2.0 \%$. The knotted fiber was 40

$2 \mathrm{~mm}$ long, and was mixed in mortar at the volume fractions of $0.5 \%, 0.75 \%$ and $1.0 \%$. The

3 volume fractions of the knotted fiber are less than those of the straight fiber because the knotted

4 fiber tends to form tenacious balls easily. The PVA and recycled PET fibers were mixed in

5 mortar at the volume fractions of $1.0 \%$ and $1.5 \%$. In this study, the uniaxial tensile tests

6 according to ASTM C1557-03 were carried out to determine Young's modulus and tensile

7 strength of recycled nylon fiber, as shown Figure 2. The appearances and properties of all the

8 fibers are summarized in Figure 1 and Table 1, respectively.

9 Firstly, cement and sand were mixed by using small mixer, and after that, fibers were gently

10 added to prevent the formation of fiber balls. To ensure uniform fiber dispersion, all dry

11 components were mixed by hand. Then, water was gradually added to the mix, and the mixing

was continued to blend all ingredients for other 2 minutes so that a homogeneous mixture and proper workability were achieved. The mass ratio of sand with cement of the mortar was 3.0 and the water-to-cement ratio was 0.5 . All molds were covered with plastic sheet to minimize moisture evaporation for a period of 24 hours after placing. Subsequently, the specimens were cured in a water tank at $20 \pm 2{ }^{\circ} \mathrm{C}$ for 28 days. As presented in Table 2 , the mortar mixes vary due

17 to types, volume and the aspect ratio of fiber. The unreinforced mortar is denoted as UR, and the 
1 length - volume fraction,” to represent recycled knotted nylon fiber, recycled straight nylon

2 fiber, recycled PET fiber and PVA fiber, respectively.

\section{$3 \quad 2.2$ Testing methods}

4 The mortar flow test was conducted in accordance with ASTM C 1437 [32]. Compressive

5 strength was determined in compliance with ASTM C 39 [33]. Flexural strength tests were

6 conducted in accordance with ASTM C 1018 [34]. The authors performed three-point bending

7 tests, and measured the peak load, first crack strength, toughness indices and residual strength

8 factors. Two Linear Variable Differential Transformer (LVDT) were used to measure deflection,

9 and were installed each side of the specimen at midspan, as shown in Figure 3. For each mix

10 design, the mortar was cast in cylinders of $50 \mathrm{~mm}$ diameter $\times 100 \mathrm{~mm}$ in height for the

11 compressive test and in prism molds of $40 \mathrm{~mm} \times 40 \mathrm{~mm} \times 160 \mathrm{~mm}$ for the bending test. For

12 each mix, three and two specimens were tested for compressive and flexural strengths,

13 respectively, after curing for 28 days.

\section{3. Results and discussions}

\section{$16 \quad 3.1$ Flowability}

17 The flow diameters were measured and are listed in Table 2. It can be seen that the flow

18 diameter tends to decrease with increase in fiber length and amount. Moreover, if comparing $1 \%$ 
1 volume fraction of straight and knotted R-nylon fiber, the fresh mortar with knotted fiber has

2 larger flow diameters. According to balling of $\mathrm{KN}$ fiber, which resulted in fiber-mortar

3 separation, the mortar easily flow. For PET and PVA fibers, mortar flows exhibited the same

4 results; that is, when the aspect ratio and fiber fraction increase, the flow diameter decreases.

5 Furthermore, if comparing R-Nylon, PET and PVA fibers at the similar aspect ratio and the

6 same fiber fraction, addition of R-Nylon, PET and PVA fibers into mortar results in more

7 reduction in mortar flowability.

$8 \quad 3.2$ Compressive strength

9 The compressive strengths of the fiber reinforced mortar at 28 days are presented in Table 3.

10 The results indicate that the compressive strength decreases as the length decreases and as the

11 amount of R-Nylon fibers increases. This can be explained that Young's modulus of mortar was

12 reduced with the dosage of fibers with low Young’s modulus, especially R-Nylon fibers [35, 36].

13 The Young's modulus of R-Nylon fiber is very low compared with that of mortar; therefore,

14 inclusion of the fiber creates voids in mortar [37]. This might suggest that the lower

15 compressive strength of the KN mortar is the result of a greater reduction in Young's modulus of

16 the fiber reinforced mortar from the inclusion of knots, see Table 3. Additionally, poor fiber

17 distribution according to easy forming ball of $\mathrm{KN}$ fiber, this results in reduction in compressive

18 strength of KN mortar. Palmquist et al. [38] found that the addition of fiber, especially long fiber, 
1 leads to increase in the volume of interfacial transition zone which results in reduction of

2 strength and stiffness of fiber reinforced mortar. Li [39] also investigated the effect of fiber

3 addition on compressive strength of cementitious composites. In this work, it can be explained

4 that a decrease of compressive strength is a result of low resistance to sliding of crack faces

5 which is exerted by bridging force of fiber. Furthermore, when the specimens are subjected to

6 compressive load, it induces lateral tensile strain in mortar due to the Poisson effect. As the load

7 increases, longer fibers play an important role in mortar's lateral tensile strength than shorter

8 ones. Therefore, the mortar postpone crack enlargement by increasing their lateral tensile

9 strength [26]. This is the reason why the addition of shorter fiber provides lower compressive

10 strength. Spadea et al. [6] also found that compressive strength of mortar with R-Nylon fiber

11 decreased with increase in fiber fraction and decrease in fiber length. For R-PET and PVA fibers,

12 the addition of these fibers into mortar reduces the mortar compressive strength. The moduli of

13 elasticity of PVA and PET fibers are close to mortar; however, these fibers have low density.

14 Therefore, mortar is mixed with large amount of fibers which results in reduction in its Young's

15 modulus [36]. According to the addition of R-Nylon fiber into mortar, the specimens

16 experienced softening behavior after the peak stress under compression test. On the other hand,

17 plain mortar showed brittle tensile split failure by the formation of the crack parallel to the

18 direction of applied load, as shown in Figure 4. 
1

2 The flexural strengths are listed in Table 3. It is evident that the addition of R-Nylon fiber

4 fraction is $1.5 \%$ for improving the flexural strength. Spadea et al. [6] found that R-Nylon fiber is

5 very effective in increasing flexural strength (up to 35\%), especially when the longer fiber is

6 used. KN, PE-30, PE-40, PV-18 and PV-30 fibers improved the flexural strength by up to 22\%,

$7 \quad 7 \%$, 22\%, 22\% and 32\%, respectively. For KN fiber, when the amounts of fiber increase, the

8 flexural strengths decrease. Because of the forming ball problem, therefore, when higher

9 amounts are used, the fiber is not well distributed which directly affects the flexural strength. In

10 case of R-PET and PVA fibers, the flexural strength increases with increase in the amount of

11 fiber.

12 It can be clearly seen in Figures 5-10 that mortar reinforced with R-Nylon shows a significant

13 reduction in load after the first crack. The second rising portion of the load-deflection curves prior

14 to the second peak, corresponded to the hardening of bond-slip behavior. This phenomenon is

15 very beneficial as long as the fiber does not break. The main reason why the R-PET fiber mortar is

16 superior in the post peak load to other types of fiber may be concerned with the fiber geometry.

17 The R-PET fiber used in this study had an embossed surface that significantly increases bond

18 strength between the fiber and mortar. Kim et al. [40] carried out an investigation focusing on the 
1 effects of R-PET fiber geometry on bond behavior with hydrated cement matrix. In the

2 mechanical bond test, the embossed fiber had considerably superior performance to the other

3 types (straight and crimped), see Table 4. In case of the PVA fiber, strong chemical bond between

4 the fiber and the hydrated cement matrix leads to break of the fiber rather than pullout from the

5 hydrated cement matrix [41, 42]. When the specimens were subjected to bending load, PVA fiber

6 tended to break before the bond failure, which caused lower post peak loads of the specimens

7 mixed with PVA fiber lower than those with R-PET fiber. In this study, the surfaces of the

8 R-Nylon, R-PET and PVA fibers were examined after the bending test to analyze the frictional

9 resistant force. As shown in Figure 11 (a), the R-Nylon fibers have no significant changes in their

10 surfaces such as scratched; therefore, friction between the fiber surface and the cement matrix is

11 poor, which leads to a decrease in frictional resistance to slippage. The R-PET surface was

12 scratched as shown in Figure 11 (b), the bond strength was enhanced due to a mechanical

13 anchorage effect in the embossed area. Moreover, since R-Nylon and R-PET fiber are softer than

14 surrounding cement matrix, a part of their surfaces were peeled, which ascended the post peak

15 load. In case of the PVA fiber, fragments of cement matrix were found on its surfaces, as shown in

16 Figure 11 (c), due to strong chemical bond. When comparing the load-midspan deflection curves

17 between SN-40-2.0 and PV-18-1.0 and 1.5, the post peak load of PV-18 gradually decreased with

18 increase in the load applied, while the post peak load of SN-40-2.0 increased and was higher than 
1 that of PV-18-2.0 deflection. Even R-Nylon fiber surface smooth, however, $40 \mathrm{~mm}$ is long

2 enough to prevent slippage due to anchor length. Such a bond improvement between fiber and

3 matrix is essential for enhancing load carrying capacity of the composite due to improvement of

$4 \quad$ stress transfer, from the matrix to fiber.

$5 \quad 3.4$ Toughness and residual strength

6 Toughness indices $I_{5}, I_{10}$ and $I_{20}$ were obtained by dividing the area under the load-deflection

7 curve up to 3.0, 5.5, and 10.5 times the first-crack deflection, respectively, by the area under the

8 curve up to the first-crack deflection, as shown in Figure 12. The residual strength factors, $R_{5,10}$

9 and $R_{10,20}$, were determined according to ASTM C1018 by the following equations:

$$
R_{5,10}=\frac{100}{(5-10)}\left(I_{5}-I_{10}\right)
$$

$$
R_{10,20}=\frac{100}{(10-20)}\left(I_{10}-I_{20}\right)
$$

The toughness indices and residual strength factors are summarized in Table 5. It is obvious that the addition of the R-Nylon fiber to the mortar appears to afford outstanding improvements in toughness, especially for higher fiber fractions and greater length of fiber as shown in Figure. 13. According to the embossed surface of the R-PET fiber, the R-PET fiber mortar performed outstanding post peak behavior; particularly the mortar with higher aspect ratio fiber (PE-40)

17 exhibited higher toughness indices and residual strength factors. This implies that not only fiber

18 length but also fiber geometries govern the bond characteristics between the fiber and cement 
1 matrix. The opposite result was obtained for the PVA fiber mortar: the smaller the aspect ratio of

2 the fiber, the higher the post peak load. Redon and Li [43] conducted a pull out test, where two

3 types of PVA fiber having $0.044 \mathrm{~mm}$ and $0.700 \mathrm{~mm}$ diameter were investigated. They found that

4 the smaller diameter fiber broke before the full pullout length, while most of the larger diameter

5 fiber were fully pulled out. Moreover, the larger diameter fiber embedded in the mortar

6 decreased in its diameter according to abrasions. Therefore, the PV-30 mortar exhibited higher

7 post peak load than the PV-18 mortar did. As evidenced by the results, the toughness and

8 residual strength of KN fiber mortar presented worst performance because the fiber fraction is

9 limited to low amount. Moreover, easily forming ball shape of KN fiber leads to poor fiber

10 distribution, which directly affects toughness and residual strength of fiber reinforced mortar.

\section{Conclusions}

13 In this study, the effectiveness and potential of using waste fishing nets as recycled nylon fiber

to reinforce mortar were experimentally tested and discussed. It can be proposed the use of nylon

short fiber recycled from waste fishing nets improves mechanical properties of mortar.

16 Compressive and three-point bending tests were performed to investigate compressive strength,

17 peak load, flexural strength, toughness indices and residual strength factors. The results of the

18 investigation demonstrated the reasonable mechanical properties of reinforced mortar with 
1 recycled nylon fiber. A possible way to recycle waste fishing nets as a mortar reinforcing material

2 can be found.

3 The following conclusions can be drawn:

4 (1) The addition of recycled nylon fiber, whether straight or knotted, results in a reduction in

5 mortar workability. However, if considering at $1 \%$ of volume fraction of recycled nylon fiber,

6 the mixes that contain knotted fiber present larger flowability. As consideration for the same

7 fiber fraction, the mixes with PVA fiber affords less flow diameter than other types of fiber at

8 the same fiber fraction and a similar fiber aspect ratio.

9 (2) The addition of every type of fiber results in a decrease in compressive strength of mortar

10 because of the low Young's modulus of the fiber. Moreover, the compressive strengths are

11 observed to be lower with higher fiber fraction and longer fibers. The addition of knotted

12 fiber leads to reductions in compressive strength of $14-44 \%$.

13 (3) The flexural strengths of $\mathrm{KN}$ and $\mathrm{SN}$ mortar are increased by up to $22-41 \%$. However, if

14 comparing flexural strengths with a $1 \%$ fiber fraction, the flexural strength of $\mathrm{KN}$ mortar is

$1537 \%$ lower than that of SN mortar. The plain mortar exhibits sudden failure as soon as its

16 stress reaches its peak, while the fiber reinforced mortar sustains stress even less than the

17 peak value with increase in deformation.

18 (4) The addition of fiber affords a more ductile mode of failure, which leads to an increase in the 
1 load carrying capacity of fiber reinforced mortar. The post peak load is observed to be higher

2 for higher fiber fractions and longer fibers.

3 (5) The characteristics of fiber such as diameter, length, geometrical shape, tensile strength and

4 Young's modulus as well as bond between the fiber and cement matrix, directly affect the

5 post peak behavior, toughness and residual strength of fiber reinforced mortar. Toughness

6 and residual strength of fiber reinforced mortar are dependent on such the characteristics of

7 fiber. The R-nylon fiber used in this study has smooth surface, which lead to poor frictional

8 resistance between fiber and matrix. On the other hand, PET fiber has embossed surface,

$9 \quad$ which significantly enhance the post peak load carrying capacity. In addition, as evidenced

10 by the results, the longer fiber improves more toughness and residual strength due to better

11 stress transferring from matrix to fiber.

12 (6) The use of knotted fiber is not practical because the fiber tends to form fiber balls and it is

13 difficult to control the fiber orientation. Therefore, the fiber fraction should be limited to use

14 in low, and as a result, it is difficult to ensure its effectiveness on the mechanical properties

15 of fiber reinforced mortar.

16 It must be noted, however, that the R-Nylon fiber reinforced mortars analyzed in this study have

17 been proven beneficial in terms of flexural strength, material toughness and residual strength as

18 virgin fiber, even if a higher fiber fraction may be required to match the performance of virgin 
1 fiber reinforced mortars. Additionally, the use of waste fishing nets as recycled nylon fiber

2 results in an environmental beneficial effect. The recycled straight nylon and recycled knotted

3 nylon fibers used in this study were cut by hand while the R-PET and PVA fibers have been

4 thoroughly treated by industrial manufactures.

5

\section{Acknowledgments}

7 This study was supported by JSPS KAKENHI Grant \#26630208. Dr. Katsufumi Hashimoto,

8 ex-Assistant Professor of Hokkaido University is greatly appreciated for his supports and advice

9 in this research.

11 References

12 [1] Sea Around Us. <http://www.seaaroundus.org> (Accessed on April 4, 2016).

13 [2] One Green Planet. <http://www.onegreenplanet.org> (Accessed on May 30, 2016).

14 [3] TriplePundit. <http://www.triplepundit.com> (Accessed on November 14, 2016)

15 [4] Coastal Plastic Recycling. <http://www.coplare.net>

16 [5] Kim Y. T., Kim, H. L. and Lee G. H. (2008). "Mechanical behavior of light soil reinforced

17 with waste fishing net.” Geotextiles and Geomembranes, 26, 512-518. 
1 [6] Spadea, S., Farina, I., Carrafiello, A. and Fraternali, F. (2015). "Recycled nylon fibers as cement mortar reinforcement.” Construction and Building Materials, 80, 200-209.

3 [7] Hughes, B. P. and Fattuhi N. I. (1976). "Improving the toughness of high strength cement paste with fibre.” Composites, 7(4), 185-188.

5 [8] Mindess, S., Banthia, N. and Benthur, A. (1986). “The response of reinforced concrete beams with a fibre concrete matrix to impact loading.” International Journal of Cement Composite and Light-Weight Concrete, 8(3), 165-170.

[9] Mindess, S. and Vondran, G. (1988). "Properties of concrete reinforced with fibrillated polypropylene fibers under impact loading.” Cement and Concrete Research, 18, 109-115.

[10] Wang, Y., Li, V. C. and Backer, S. (1990). “Tensile properties of synthetic fiber reinforced mortar.” Cement and Concrete Composites, 12(1), 29-40.

[11] Alhozaimy, A. M., Soroushian, P. and Mirza, F. (1996). "Mechanical properties of polypropylene fiber reinforced concrete and the effects of pozzolanic materials.” Cement and Concrete Composites, 18(2), 85-92. polypropylene-fiber-reinforced concretes.” Cement and Concrete Research, 35(8), 1546-1550. 
1 [13] Ozerkan, N. G., Ahsan, B., Mansour, S. and Iyengar, S. R. (2013). "Mechanical performance and durability of treated palm fiber reinforced mortars.” International Journal of Sustainable Building Environment, 2(2), 131-142.

[14] Banthia, N., Zanotti, C. and Sappakittikorn, M. (2014). "Sustainable fiber reinforced concrete for repair applications." Construction and Building Materials, 67 (Part C), 405-412.

[15] Jang, J. G., Kim, H. K., Kim, T. S., Min, B. J. and Lee, H. K. (2014). “Improved flexural fatigue resistance of PVA fiber-reinforced concrete subjected to freezing and thawing cycles.” Construction and Building Materials, 59, 129-135.

[16] Kwon, M. H., Jung, W. Y. and Seo, H. S. (2014). "The flexural strength of fiber reinforced polymer cement mortars with using UM resin.” International Journal of Civil, Environmental, Structural, Construction and Architectural Engineering, 8(2), 127-130.

[17] Erdogmus, E. (2015). "Use of fiber reinforced cements in masonry construction and structural rehabilitation.” Fibers, 3, 41-63 (doi:10.3390/fib3010041).

[18] El-Gamal, S. E., Al-Nuaimi, A., Al-Saidy, A. and Al-Lawati, A. (2016). "Efficiency of near surface mounted technique using fiber reinforced polymers for the flexural strengthening of RC beams.” Construction and Building Materials, 118, 52-62. 
1 [19] Khan, U. S. and Ayub, T. (2016). "Modelling of the pre and post-cracking response of the

PVA fibre reinforced concrete subjected to direct tension.” Construction and Building Materials, 120, 540-557.

[20] Mohseni, E., Khotbehsara, M. M., Naseri, F., Monazami, M. and Sarker, P. (2016). "Polypropylene fiber reinforced cement mortars containing rice husk ash and nano-alumina.” Construction and Building Material, 111, 429-439.

[21] Yin, W., Tuladhar, R., Riella, J., Chung, D., Collister, T. and Combe, M. (2016). “Comparative evaluation of virgin and recycled polypropylene fibre reinforced concrete.” Construction and Building Materials, 114, 134-141.

[22] Nuruddin, M. F., Khan, S. U., Shafiq, N. and Ayub, T. (2014). "Strength development of high strength ductile concrete incorporating Metakaolin and PVA fibers.” The Scientific World Journal, 2014, Article \#387259, 1-11.

[23] Silva, D. A., Betioli, A. M., Gleize, P. J. P., Roman, H. R., Gomez, L. A. and Ribeiro, J. L. D. (2005). "Degradation of recycled PET fibers in Portland cement-based materials.” Cement and Concrete Research, 35(8), 1741-1746.

[24] Foti, D. (2011). "Preliminary analysis of concrete reinforced with waste bottles PET fibers.” Construction and Building Materials, 25, 1906-1915. 
1 [25] Pereira de Olivia, L. A. and Castro-Gomes, J. P. (2011). "Physical and mechanical behavior of recycled PET fibre reinforced mortar.” Construction and Building Materials, $25,1712-1717$

[26] Fraternali, F., Farina, I., Polzone, C., Pagliuca, E. and Feo, L. (2013). “On the use of R-PET strips for reinforcement of cement mortars.” Composites B. 46, 207-210.

[27] Habib, A., Begum, R. and Alam, M. M. (2013). "Mechanical properties of synthetic fibers reinforced mortars.” Internal Journal of Scientific and Engineering Research, 4(4), 923-927.

[28] Ozger, O. B., Girardi, F., Giannuzzi, G. M., Salomoni, V. A., Majorana, C. E., Fambri, L., Baldassino, N. and Maggio, R. D. (2013). "Effect of nylon fibers on mechanical and thermal properties of hardened concrete for energy storage systems.” Materials and Design, 51, 989-997.

[29] Pesic, N., Zivanovic, S., Garcia, R. and Papastergiou, P. (2016). “Mechanical properties of concrete reinforced with recycled HDPE plastic fibres.” Construction and Building Materials, 115, 362-370.

[30] Ochi, T., Okubo, S. and Fukui, K. (2007). "Development of recycled PET fiber and its application as concrete-reinforcing fiber.” Cement and Concrete Composites, 29, 448-455. 
1 [31] Orasutthikul, S., Unno, D., Yokota, H. and Hashimoto, K. (2016). "Effectiveness of recycled nylon fiber as a reinforcing material in mortar.” Proceedings of the 7th International Conference of Asian Concrete Federation, 30 Oct - 2 Nov, Hanoi, Vietnam.

[32] ASTM C 1437. "Standard test method for flow of hydraulic cement mortar." ASTM International, West Conshohocken, PA.

[33] ASTM C 39. "Standard test method for compressive strength of cylindrical compressive specimens.” ASTM International, West Conshohocken, PA.

[34] ASTM C 1018. "Standard test method for flexural toughness and first-crack strength of fiber reinforced concrete.” ASTM International, West Conshohocken, PA.

[35] Wang, Y., Wu, H. C. and Li, V. C. (2000). “Concrete reinforcement with recycled fibers.” Journal of Materials in Civil Engineering, 12(4), 314-319.

[36] Hu, W., Yang, X., Zhou, J., Xing, H. and Xiang, J. (2013). "Experimental research on the mechanical properties of PVA fiber reinforced concrete.” Research Journal of Applied Science, Engineering and Technology, 5(18), 4563-4567.

[37] Karahan, O. and Atis, C. D. (2011). “The durability properties of polypropylene fiber reinforced fly ash concrete.” Materials and Design, 32(2), 1044-1049. 
1 [38] Palmquist, S. M., Kintzel, E. and Andrew, K. (2011). "Scanning electron microscopy to

2

examine concrete with carbon nanofibers.” Proceedings of the 5th Pan American Conference for NDT, Cancun, Mexico.

[39] Li, V. C. (1992). “A simplified micromechanical model of compressive strength of fiber-reinforced cementitious composites.” Cement and Concrete Composites, 14, $131-141$.

[40] Kim, J. H. J., Park, C. G., Lee, S. W., Lee, S. W. and Won, J. P. (2008). "Effects of the geometry of recycled PET fiber reinforcement on shrinkage cracking of cement-based composites.” Composites B, 39, 442-450.

[41] Nematollahi, B., Sanjaya, J. and Ahmed Shaikh, F. U. (2015). "Tensile strain hardening behavior of PVA fiber-reinforced engineered geopolymer composite.” Journal of Materials in Civil Engineering, 27(10) (doi: 1943-5533.0001242).

[42] Jewell, R. B., Mahboub, K. C., Robl, T. L. and Bathke, A. C. (2015). "Interfacial bond between reinforcing fibers and calcium sulfoaluminate cements: fiber pullout characteristics.” ACI Materials Journal, 112(1), 38-47.

[43] Redon, C. and Li, V. C. (2001). "Measuring and modifying interface properties of PVA fibers in ECC matrix.” Journal of Materials in Civil Engineering, 13(6), 399-406. 
Table 1 Properties of the fibers.

\begin{tabular}{|c|c|c|c|c|}
\hline Fiber type & $\begin{array}{c}\text { Diameter } \\
(\mathrm{mm})\end{array}$ & $\begin{array}{c}\text { Tensile strength } \\
(\mathrm{MPa})\end{array}$ & $\begin{array}{c}\text { Young's modulus } \\
(\mathrm{GPa})\end{array}$ & $\begin{array}{c}\text { Density } \\
\left(\mathrm{g} / \mathrm{cm}^{3}\right)\end{array}$ \\
\hline R-Nylon & 0.35 & 440 & 3.0 & 1.13 \\
\hline R-PET & 0.70 & 450 & 20 & 1.32 \\
\hline PVA $(18 \mathrm{~mm})$ & 0.20 & 975 & 27 & 1.30 \\
\hline PVA $(30 \mathrm{~mm})$ & 0.66 & 900 & 23 & 1.30 \\
\hline
\end{tabular}

4 Table 2 Specimen types and test results of mortar flow.

\begin{tabular}{|c|c|c|c|c|c|}
\hline Specimen type & $\begin{array}{l}\text { Fiber fraction } \\
\text { by volume (\%) }\end{array}$ & $\begin{array}{l}\text { Fiber length } \\
(L)(\mathrm{mm})\end{array}$ & $\begin{array}{l}\text { Fiber diameter } \\
(D)(\mathrm{mm})\end{array}$ & $\begin{array}{l}\text { Aspect ratio } \\
(L / D)\end{array}$ & $\begin{array}{l}\text { Mortar flow } \\
(\mathrm{mm})\end{array}$ \\
\hline UR & 0 & - & - & - & 260 \\
\hline KN-40-0.5 & 0.5 & 40 & 0.35 & 114 & 247 \\
\hline KN-40-0.75 & 0.75 & 40 & 0.35 & 114 & 233 \\
\hline $\mathrm{KN}-40-1.0$ & 1.0 & 40 & 0.35 & 114 & 227 \\
\hline SN-20-1.0 & 1.0 & 20 & 0.35 & 57 & 231 \\
\hline SN-20-1.5 & 1.5 & 20 & 0.35 & 57 & 226 \\
\hline SN-20-2.0 & 2.0 & 20 & 0.35 & 57 & 207 \\
\hline SN-30-1.0 & 1.0 & 30 & 0.35 & 86 & 229 \\
\hline SN-30-1.5 & 1.5 & 30 & 0.35 & 86 & 216 \\
\hline SN-30-2.0 & 2.0 & 30 & 0.35 & 86 & 195 \\
\hline SN-40-1.0 & 1.0 & 40 & 0.35 & 114 & 217 \\
\hline SN-40-1.5 & 1.5 & 40 & 0.35 & 114 & 207 \\
\hline SN-40-2.0 & 2.0 & 40 & 0.35 & 114 & 183 \\
\hline PE-30-1.0 & 1.0 & 30 & 0.70 & 43 & 244 \\
\hline PE-30-1.5 & 1.5 & 30 & 0.70 & 43 & 219 \\
\hline PE-40-1.0 & 1.0 & 40 & 0.70 & 57 & 229 \\
\hline PE-40-1.5 & 1.5 & 40 & 0.70 & 57 & 196 \\
\hline PV-18-1.0 & 1.0 & 18 & 0.20 & 90 & 213 \\
\hline PV-18-1.5 & 1.5 & 18 & 0.20 & 90 & 169 \\
\hline PV-30-1.0 & 1.0 & 30 & 0.66 & 45 & 213 \\
\hline PV-30-1.5 & 1.5 & 30 & 0.66 & 45 & 189 \\
\hline
\end{tabular}


Table 3 Results of compressive strength and flexural strength tests.

\begin{tabular}{|c|c|c|c|c|c|c|c|c|}
\hline \multirow[b]{2}{*}{ Specimen type } & \multicolumn{4}{|c|}{ Compressive strength test } & \multicolumn{4}{|c|}{ Flexural strength test } \\
\hline & $\begin{array}{c}f_{c}^{\prime} \\
(\mathrm{MPa})\end{array}$ & $\begin{array}{c}S D \\
(\mathrm{MPa})\end{array}$ & $\begin{array}{l}C V \\
(\%)\end{array}$ & $\begin{array}{l}\Delta f_{c}^{\prime} \\
(\%)\end{array}$ & $\begin{array}{c}f_{b} \\
(\mathrm{MPa})\end{array}$ & $\begin{array}{c}S D \\
(\mathrm{MPa})\end{array}$ & $\begin{array}{l}C V \\
(\%)\end{array}$ & $\begin{array}{l}\Delta f_{b} \\
(\%)\end{array}$ \\
\hline UR & 65.7 & 1.5 & 2.3 & - & 4.8 & 0.1 & 3.4 & - \\
\hline KN-40-0.5 & 56.6 & 6.9 & 12.1 & -13.8 & 5.9 & 0.1 & 5.7 & 22.0 \\
\hline KN-40-0.75 & 56.0 & 11.4 & 20.4 & -14.9 & 5.0 & 0.1 & 3.3 & 4.9 \\
\hline $\mathrm{KN}-40-1.0$ & 36.8 & 6.0 & 16.2 & -44.0 & 4.5 & 0.0 & 0.0 & -7.4 \\
\hline SN-20-1.0 & 52.6 & 1.2 & 2.2 & -20.0 & 6.1 & 0.1 & 5.5 & 26.8 \\
\hline SN-20-1.5 & 48.7 & 2.1 & 4.2 & -25.9 & 6.8 & 0.2 & 9.7 & 41.4 \\
\hline SN-20-2.0 & 34.1 & 1.7 & 5.0 & -48.0 & 4.8 & 0.1 & 3.4 & -0.1 \\
\hline SN-30-1.0 & 53.6 & 0.6 & 1.1 & -18.4 & 5.7 & 0.2 & 8.7 & 19.4 \\
\hline SN-30-1.5 & 46.8 & 1.0 & 2.2 & -28.7 & 5.6 & 0.1 & 5.9 & 17.1 \\
\hline SN-30-2.0 & 35.1 & 3.3 & 9.5 & -46.6 & 4.3 & 0.2 & 11.5 & -9.8 \\
\hline SN-40-1.0 & 55.5 & 2.8 & 5.1 & -15.4 & 6.0 & 0.2 & 8.3 & 24.4 \\
\hline SN-40-1.5 & 48.2 & 0.6 & 1.2 & -26.5 & 6.4 & 0.1 & 2.5 & 34.0 \\
\hline SN-40-2.0 & 35.3 & 1.1 & 3.0 & -46.3 & 5.2 & 0.1 & 6.4 & 7.3 \\
\hline PE-30-1.0 & 65.2 & 0.4 & 0.6 & -0.5 & 4.9 & 0.0 & 0.0 & 2.4 \\
\hline PE-30-1.5 & 60.2 & 5.0 & 8.4 & -8.2 & 5.2 & 0.4 & 19.2 & 7.3 \\
\hline PE-40-1.0 & 66.2 & 0.7 & 1.1 & 1.0 & 5.3 & 0.1 & 3.2 & 9.7 \\
\hline PE-40-1.5 & 60.8 & 5.1 & 8.4 & -7.2 & 5.9 & 0.4 & 17.0 & 21.9 \\
\hline PV-18-1.0 & 62.9 & 1.9 & 2.9 & -4.0 & 5.7 & 0.1 & 2.9 & 19.5 \\
\hline PV-18-1.5 & 62.5 & 0.9 & 1.4 & -4.6 & 5.9 & 0.1 & 5.7 & 22.0 \\
\hline PV-30-1.0 & 62.2 & 2.1 & 3.3 & -5.1 & 5.6 & 0.5 & 23.6 & 17.1 \\
\hline PV-30-1.5 & 61.1 & 2.9 & 4.8 & -6.8 & 6.3 & 0.0 & 0.0 & 31.7 \\
\hline
\end{tabular}

2

3 Note) $f^{\prime}{ }_{c}$ is compressive strength; $f_{b}$ is flexural strength; $S D$ is standard deviation; $C V$ is the coefficient of 4 variation; and $\Delta f^{\prime}{ }_{c}$ and $\Delta f_{b}$ are the percent difference in compressive strength and in flexural strength in 5 comparison with respective control specimens (UR). 
1 Table 4 Mechanical bond strength tested by Kim et al. [40].

\begin{tabular}{lccc}
\hline Fiber geometry & Straight & Crimped & Embossed \\
\hline Mechanical bond strength (MPa) & 1.7 & 3.9 & 5.0 \\
\hline
\end{tabular}

Table 5 Toughness indices and residual strength factors at 28 days.

\begin{tabular}{|c|c|c|c|c|c|}
\hline \multirow{2}{*}{ Specimen type } & \multicolumn{3}{|c|}{ Toughness index } & \multicolumn{2}{c|}{ Residual strength factor } \\
\cline { 2 - 6 } & $I_{5}$ & $I_{10}$ & $I_{20}$ & $R_{5,10}$ & $R_{10,20}$ \\
\hline KN-40-0.5 & 1.61 & 1.82 & 2.42 & 4.20 & 6.02 \\
\hline KN-40-0.75 & 1.56 & 2.20 & 4.00 & 12.80 & 18.01 \\
\hline KN-40-1.0 & 1.91 & 3.27 & 6.21 & 27.20 & 29.43 \\
\hline SN-20-1.0 & 1.95 & 2.41 & 3.45 & 9.18 & 10.40 \\
\hline SN-20-1.5 & 2.40 & 3.38 & 5.23 & 19.50 & 18.50 \\
\hline SN-20-2.0 & 2.80 & 4.17 & 6.71 & 27.30 & 25.40 \\
\hline SN-30-1.0 & 1.97 & 2.91 & 4.79 & 18.80 & 18.80 \\
\hline SN-30-1.5 & 2.86 & 4.17 & 6.49 & 26.20 & 22.85 \\
\hline SN-30-2.0 & 3.05 & 4.23 & 7.29 & 23.60 & 30.61 \\
\hline SN-40-1.0 & 2.88 & 4.47 & 7.71 & 31.90 & 32.44 \\
\hline SN-40-1.5 & 2.49 & 4.25 & 7.80 & 35.18 & 35.42 \\
\hline SN-40-2.0 & 3.37 & 6.02 & 13.38 & 53.00 & 73.60 \\
\hline PE-30-1.0 & 3.15 & 5.99 & 13.03 & 56.94 & 70.34 \\
\hline PE-30-1.5 & 4.36 & 9.22 & 20.80 & 97.02 & 115.85 \\
\hline PE-40-1.0 & 5.07 & 11.29 & 25.60 & 124.26 & 143.10 \\
\hline PE-40-1.5 & 4.68 & 9.91 & 22.41 & 104.58 & 125.05 \\
\hline PV-18-1.0 & 2.77 & 4.62 & 8.74 & 37.00 & 41.21 \\
\hline PV-18-1.5 & 3.72 & 7.50 & 15.74 & 75.60 & 82.40 \\
\hline PV-30-1.0 & 5.09 & 11.33 & 20.58 & 124.74 & 92.50 \\
\hline PV-30-1.5 & 5.06 & 11.16 & 24.86 & 121.88 & 137.04 \\
\hline
\end{tabular}

5

6 
1

2

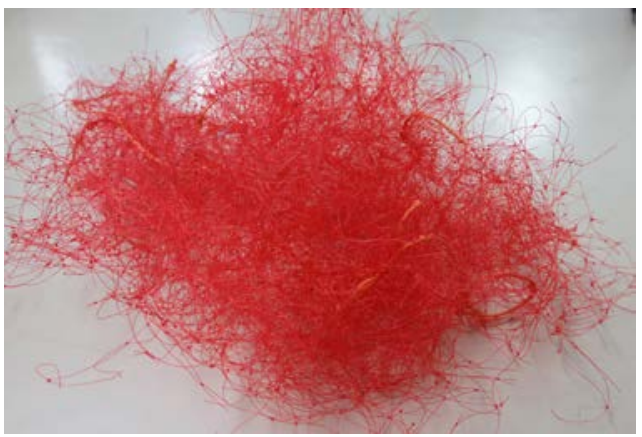

(a) Waste fishing net

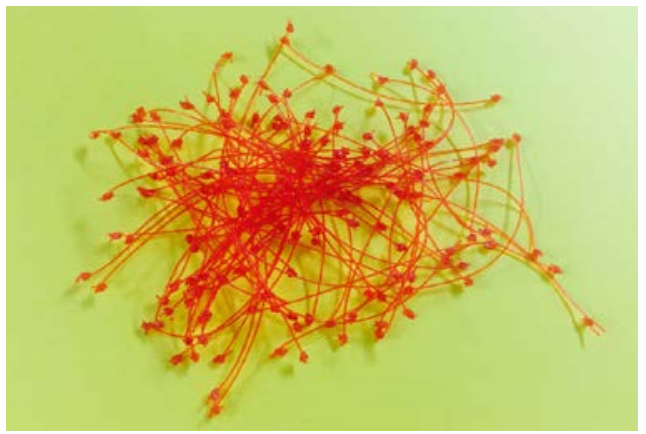

(c) Knotted R-Nylon fiber

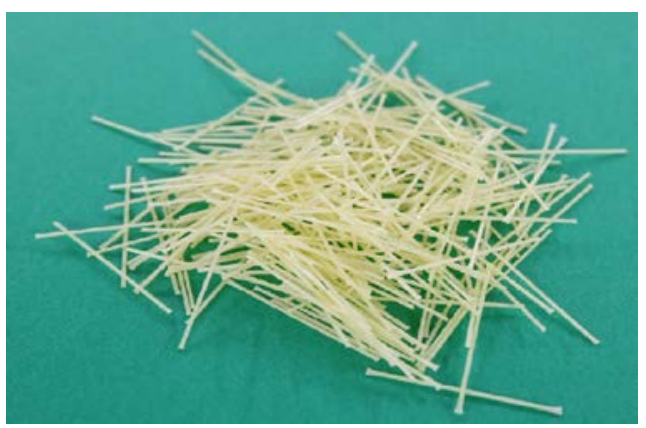

(e) PVA fiber (30 mm)

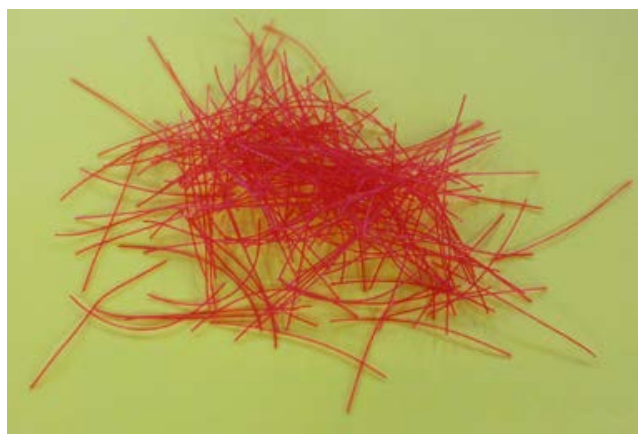

(b) Straight R-Nylon fiber

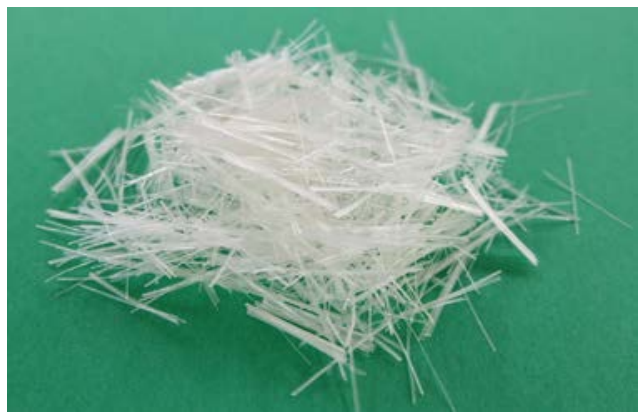

(d) PVA fiber (18 mm)

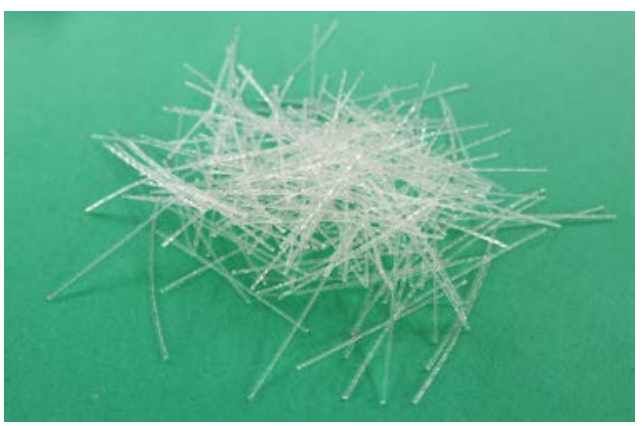

(f) R-PET fiber
6

7

8

9

10

11 

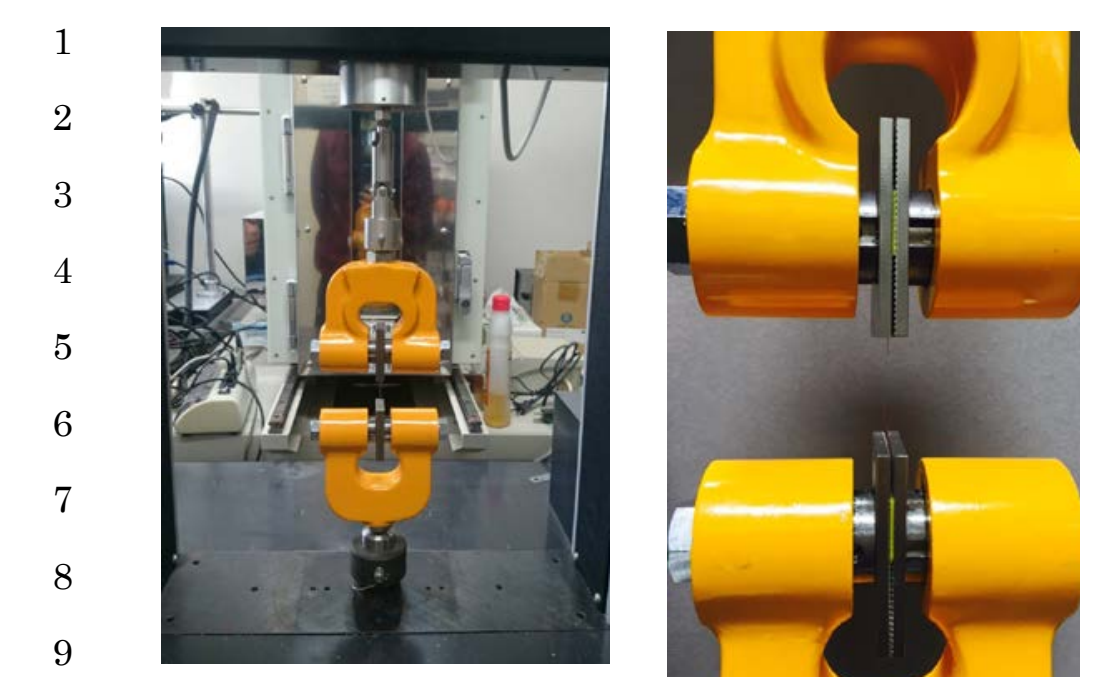

Figure 2 Uniaxial tensile test

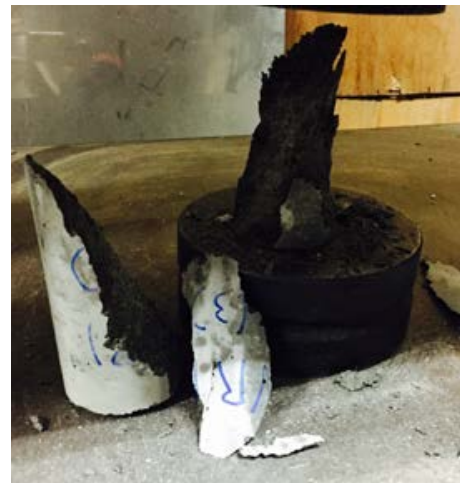

(a) Plain mortar

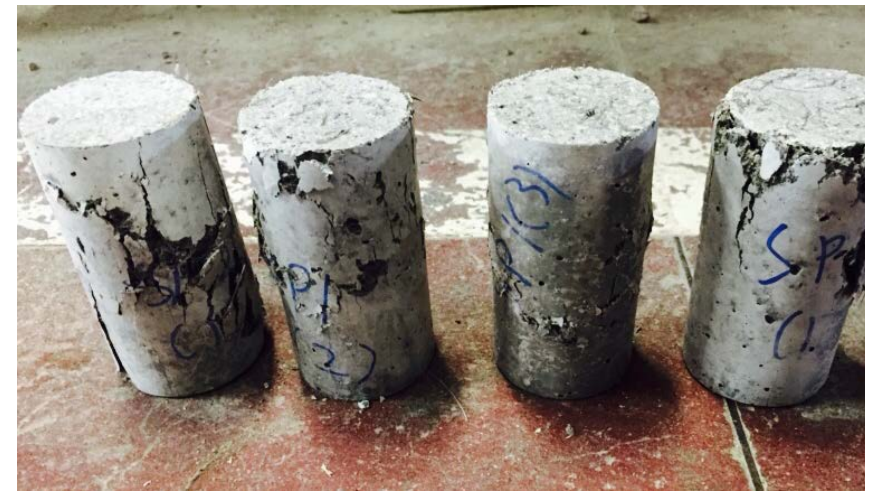

(b) R-nylon fiber reinforced mortar

Figure 4 Failure modes of non-reinforced and reinforced mortar by compressive test. 


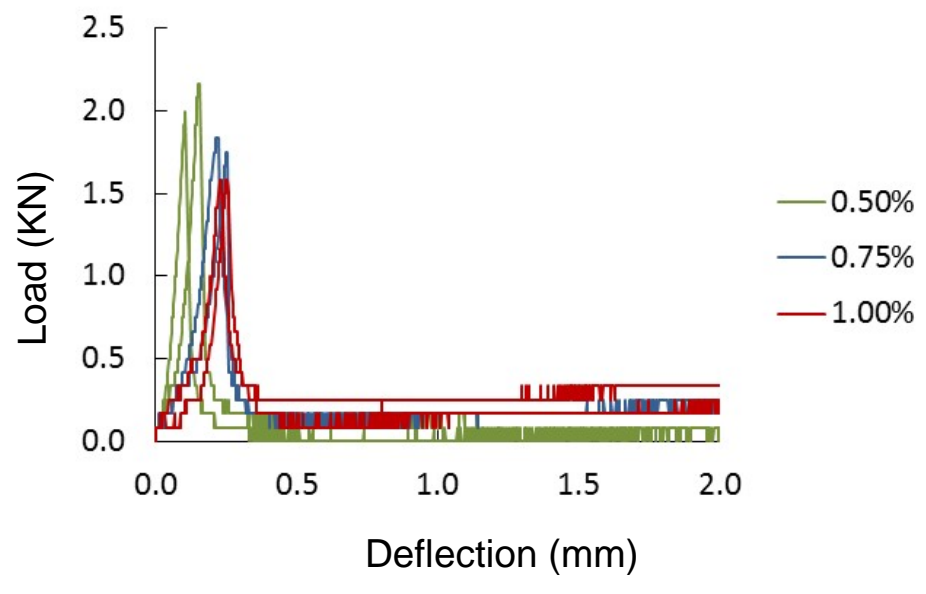

Figure 5 Load-midspan deflection curves of mortar specimens reinforced with knotted 3 R-Nylon fiber.

4

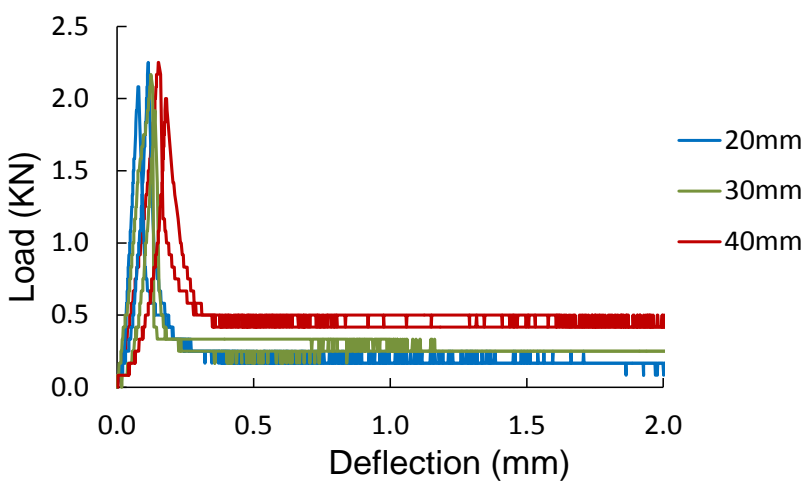

6 Figure 6 Load-midspan deflection curves of mortar specimens reinforced with straight 7 R-Nylon fiber with $\mathbf{1 . 0} \%$ fiber fraction.

8

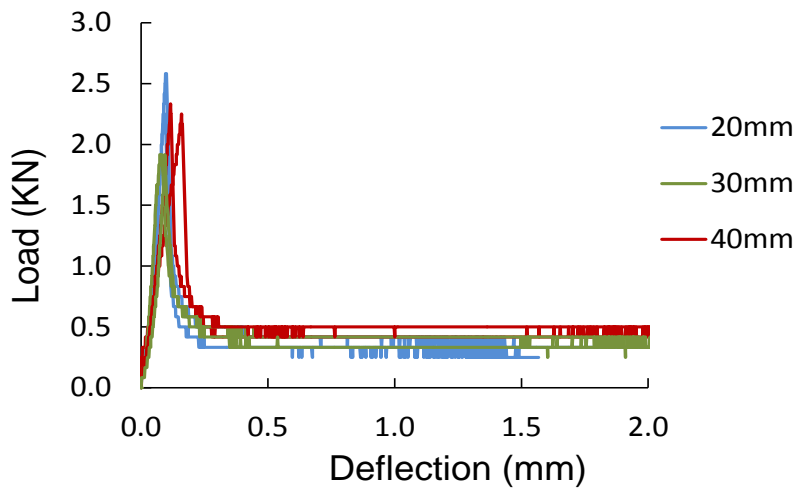

10 Figure 7 Load-midspan deflection curves of mortar specimens reinforced with straight 11 R-Nylon fiber with $\mathbf{1 . 5 \%}$ fiber fraction. 


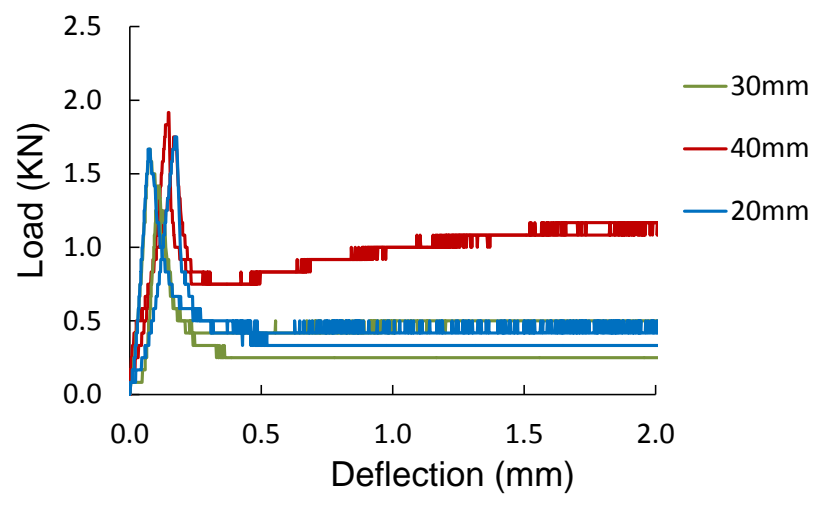

2 Figure 8 Load-midspan deflection curves of mortar specimens reinforced with straight 3 R-Nylon fiber with $\mathbf{2 . 0} \%$ fiber fraction.

4

5

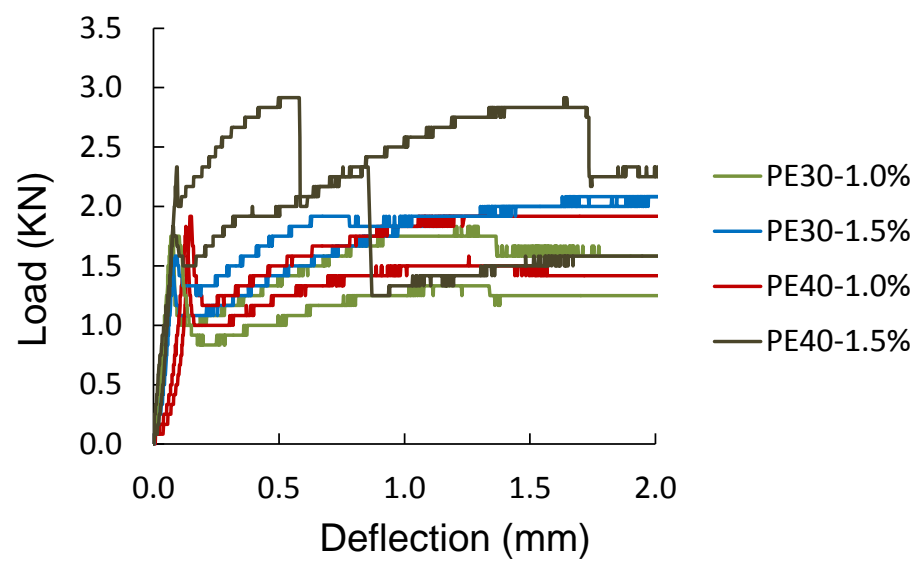

6 Figure 9 Load-midspan deflection curves of mortar specimens reinforced with R-PET 7 fiber.

8

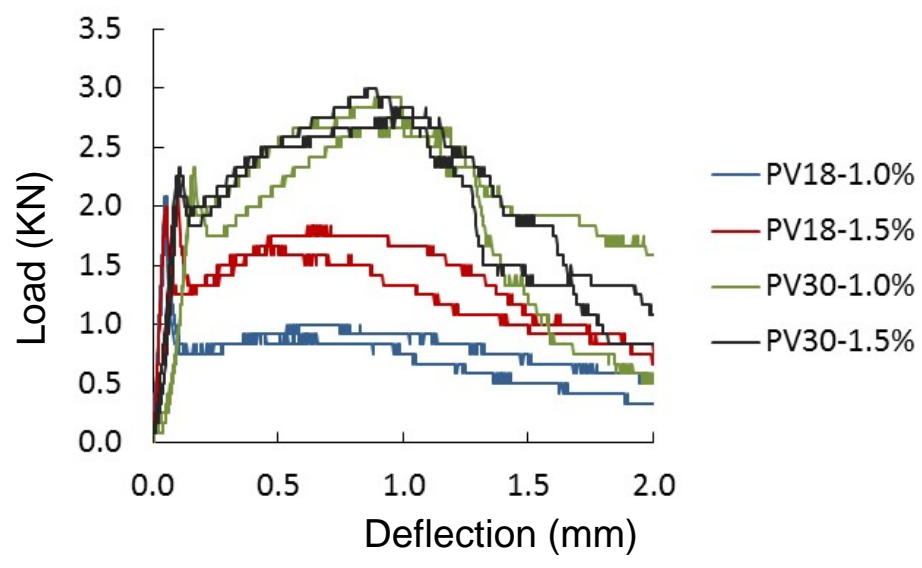

10 Figure 10 Load-midspan deflection curves of mortar specimens reinforced with PVA fiber. 

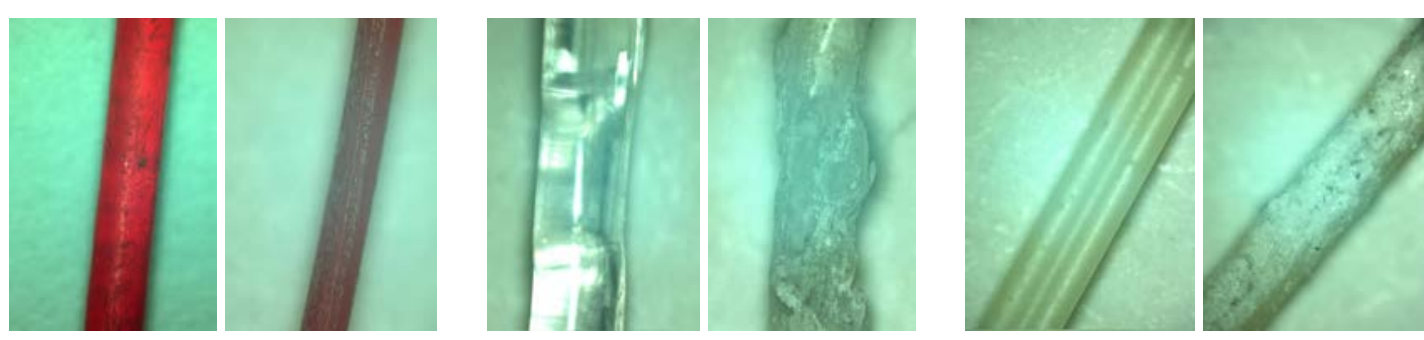

(a) Before After

(b) Before

After

(c) Before

After

8 fiber and (c) PVA fiber (30 mm).

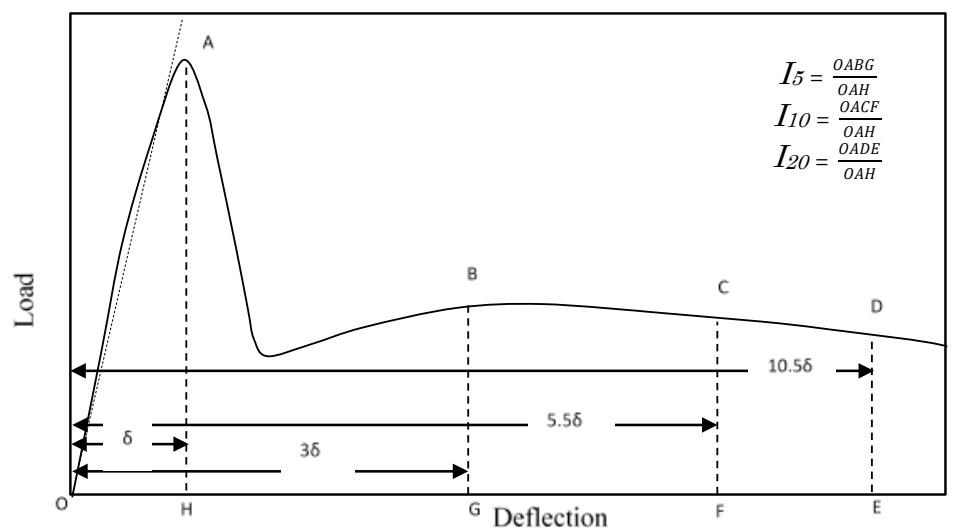

10

Figure 12 Toughness indices as defined by ASTM 1018 [34].
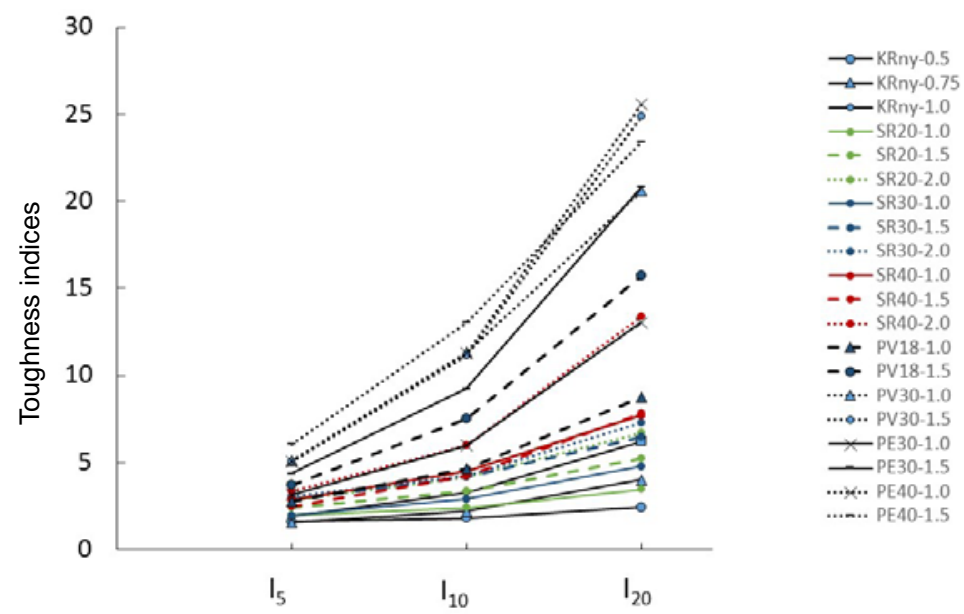

Figure 13. Toughness indices of fiber reinforced mortars. 